\title{
İlköğretim Öğrencilerinin Görsel Okuma Becerisi ile Okuduğunu Anlama Becerisi Arasındaki İlișkinin İncelenmesi
}

\begin{abstract}
Özlem BAŞ
Nergiz KARDAŞ

Özet

İlköğretim öğrencilerinin görsel okuma becerisi ile okuduğunu anlama becerisi arasındaki ilişkinin incelenmesini amaçlayan bu araştırmada ilişkisel model kullanılmıştır. Araştırmanın örneklemini, Ankara ili Çankaya ilçesinde basit seçkisiz örnekleme yöntemi kullanılarak seçilmiş 52 dördüncü sınıf öğrencisi oluşturmaktadır. Araştırmada, öğrencilerin görsel okuma becerisini ölçmeye yönelik Pixar tarafından üretilmiş beş adet grafik animasyon türü kısa filme yönelik görsel okuma testi ve okuduğunu anlama becerisini ölçmeye yönelik okuduğunu anlama testi geliştirilmiştir. Görsel okuma testinin geçerlik güvenirlik değerlerinin belirlenmesi için 273 öğrenciye uygulanmıştır ve güvenirlik analizi sonucunda elde edilen cronbach alpha katsayıları. 80'in üzerindedir. Araştırmanın bulguları; ilköğretim dördüncü sınıf öğrencilerinin görsel okuma becerisi testi ile okuduğunu anlama becerisi testinden elde ettikleri toplam puanları arasında [ $r=.44]$ pozitif yönde anlamlı ilişki olduğunu göstermektedir.
\end{abstract}

Anahtar Kelimeler: Görsel okuma, okuduğunu anlama, Pixar

The Relationship between Primary School Students' Visual Literacy Skills and Reading Comprehension Skills

\footnotetext{
Abstract

Relational method was employed in this study which aims to analyze the relationship between visual reading skill and reading comprehension skill of primary school students. This research was conducted among 52 fourth grade students who were selected through simple random sampling method from Ankara, Çankaya district. In this research, visual reading test on five animated short movies by Pixar to assess visual reading skill of students and reading comprehension test to assess

${ }^{*}$ Uzman Dr , Hacettepe Üniversitesi, Eğitim Fakültesi, Sınıf Öğretmenliği Ana Bilim Dali

** Arş. Gör., Hacettepe Üniversitesi, Eğitim Fakültesi, Sınıf Öğretmenliği Ana Bilim Dalı
} 
reading comprehension of students were developed. Visual reading test was given to 273 students in order to determine validity and reliability values and the cronbach's alpha coefficient obtained by the reliability analysis is above .80 . Research findings indicate that there is a positive significant relation between total scores $[r=.44]$ of primary school fourth grade students in visual reading test and reading comprehension test.

Key Words: Visual literacy, reading comprehension, Pixar

\section{Giriş}

Yüzyıllar önce mağara duvarlarına kendini ifade etmek ve iletişim kurmak için yapılan görseller günümüz şehirlerinin caddelerinde çok renkli grafitilere dönüşmüştür. Mısır hiyerogliflerine uzanan ideogram, görsel yazı tipi bugün Çin ve Japonya'da halen varlığını sürdürmektedir. Sokağa çıktığımızda karşılaştı̆̆ımız levhalar, işaretler, ilanlar, posterler her türlü sözel olmayan mesaj görsel okumanın hayatımızın ne kadar içinde olduğunu göstermektedir. Peki tam anlamıyla nedir görsel okuryazarlık?

Debes (1968) görsel okuryazarlık tanımını ilk kez ortaya koyan kişi olarak görsel okuryazarlığı şu şekilde tanımlamıştır:

" Görsel okuryazarlık birçok alandaki bilginin, teknoloji ve teorinin bir araya gelmesiyle temellenir." (akt. Hortin, 1994,5)

Debes'e ait diğer bir tanımlama da şu şekildedir:

"Görsel okuryazarlık bir dizi görme yeteneğinin gelişmesi sonucunda insanın görme ile aynı zamanda diğer duyusal deneyimleri birleştirmesi sonucu oluşrmaktadır." (akt. Shurtleff, 2006,15)

Görsel okuryazarlık teorisi temelde dilbilim, sanat, psikoloji ve felsefe bilim dallarından etkilenmiştir. Hortin $(1994,22)$ bu teorinin ortaya çıkması sürecindeki fikirleri şu şekilde aktarmaktadır: Dilbilimde Fries (1952) sözel dildeki anlamın sözel yapılar ve elementlerden türediğini ileri sürmektedir. Fries'in (1952) düşüncesi görsel okuma eğitimini temellendirmiştir. Görsel okuryazarlığa göre görsel elementler; renk, biçim, anlam ve kompozisyon görsel bilginin içerisinde anlamlandırılır. Chomsky'nin fikirleri de görsel okuryazarlı kavramına katkı sağlamaktadır. Gozemba (1975) Chomsky'nin evrensel gramer teorisine göre, eğer sözel dilde evrensellik varsa görsel dilin de evrensel olacağını iddia etmiştir. Psikoloji alanında yapılan çalışmalar görsel algının kendisinin bir öğrenme biçimi olduğunu ileri sürmektedir. Gibson (1954) görsel algının gelişmesi gerektiğinin önemine dikkat çekmiştir. Arnheim'ın (1969) teorisi ise görsel düşünme üzerinedir. Ona göre görsel okuryazarlığın anlamı görsel düşünmedir, görsel elemanlardan oluşan bilginin işlenme 
sürecidir. Görsel okuryazarlık kavramıla ilişkili önemli teorilerden biri de İkili Kodlama Teorisidir. 1971 yılında Allen Paivio tarafından ortaya konulmuş teoriye göre insanların öğrenmesinde sözel ilişkiler ve görsel imajlar olmak üzere iki kanal vardır (Epçaçan, Epçaçan ve Ulaş, 2010; Wikipedi, 2013) Paivio (1991, 326) bu sistemleri şu şekilde açıklamaktadır. Birinci sistem görsel sistem, duyusal bilginin sözel olmayan objeler üzerindeki merakıdır, böylece zihinsel imajlar elde eder. İkinci sistem sözel sistem, dille ilgili bilgiyi ve konuşmayı yapılandırmayı sağlamaktadır. Birbirine dayanan ve birbiriyle bağlantılı olan bu iki sistem sunulan bilginin organize olmasını ve üst yapılarda anlamlandırılmasını sağlar.

20 yy. da görüntü üretme, işleme ve çoğaltma teknolojilerinde gerçekleşen gelişmeler, görsellerin hemen her alanda yaygin bir şekilde kullanılmaya başlanmasına neden olmuştur (Yıldız, 2012). İletişimde görsel öğelerin kullanılması, onları okuyabilme yani görsel okuryazar olmayı gerekli hale getirmektedir. Metin ve resimler arasında; yazılı ve figüratif dünyalar arasında ince ve akıcı bir şekilde hareket edilmelidir (İşler,2002, 159).

Türkçe Öğretim Programı'nda $(2005,21)$ görsel okuma ve görsel sunu ayrı bir öğrenme alanı olarak ilk kez ele alınmıştır. Bu öğrenme alanı şekil, sembol, resim, grafik, tablo, beden dili, doğa ve sosyal olayların görsellerini okuma, anlama ve yorumlamayı kapsamaktadır. Ayrica öğrencilerin duygu, düşünce ve bilgilerini görseller aracılığıyla başkalarına aktarması bu alan içinde ele alınmıştır. Öğretmenlerin bu konuda iyi yetiştirilmesi ve okullarda gerekli donanım desteği sağlandığında, öğrenciyi hayata hazırlamasında önemli katkılar sağlanabilecektir. (Akpınar, 2009:47). Balur (2008) ilköğretim birinci kademede uygulanan görsel okuma ve görsel sunu öğrenme alanının Türkçe öğretiminde kazanımlara ulaşmada etkililiğine ilişkin araştırmasında öğretmenler, görsel okuma ve görsel sunu alanını yöntem ve tekniklerde çeşitlilik sağlaması, görselliğe dayalı kalıcılık sağlaması bakımından yeterli bulurken; görsel etkinliklerin verimli bir şekilde uygulanabilmesi için okulların yeterli imkân ve donanıma sahip olmadığını belirtmiştir.

Kuru'nun (2008) araştırmasının sonuçlarına göre; öğretmenlerin çoğunluğu öğrencilerin görsel okuma ve görsel sunu becerilerini kazanmaktan zevk aldığı, bu becerilerin Türkçe dersine olan ilgiyi artırdığını, bilgilerin kalıcılığını sağladığını ve öğrencilerin yaparak yaşayarak öğrenmesine katkıda bulunduğunu belirtmişlerdir. Sonuç olarak öğretmenler kendilerini görsel okuma ve görsel sunu becerileri konusunda yeterli görmediklerini ancak bu becerilerin kazanılmasının gerekli olduğunu ifade etmişlerdir. 
Etkili bir görsel tasarıma sahip olan bir öğretim materyalinin başta güdüleyici olmak üzere, tüm özelliklerinin öğrencinin başarısını artırması ve öğrencinin derse yönelik tutumlarını olumlu yönde etkilemesi beklenir (Tüzel, 2010, 98)Animasyon filmler özellikle ilköğretim öğrencilerinin ilgisini çekme ve merak duygusunu canlı tutması yönleriyle oldukça kullanışlı görsel materyallerdir. Bu araştırmada görsel okuma becerisini işe koşmak amacıyla Pixar firmasının hazırladığı grafik animasyon filmleri kullanılmıştır. Belirli bir ana fikir etrafında toplam dört beş dakika süren filmler tamamen görsel imajların anlamlandırılması üzerine tasarlanmıştır.

\section{Araştırmanın Amacı}

İlköğretim öğrencilerinin görsel okuma becerisi ile okuduğunu anlama becerisi arasındaki ilişkinin incelenmesini amaçlayan bu araştırma kısa filmlerin eğitim amaçlı kullanılmasını sağlaması ve alan yazına katkı sağlaması bakımından önem teşkil etmektedir. Araştırmada şu soruya cevap aranmıştır:

İlköğretim öğrencilerinin görsel okuma becerisi ile okuduğunu anlama becerisi arasında bir ilişki var mıdır?

\section{YÖNTEM}

\section{Araştırmanın Modeli}

$\mathrm{Bu}$ araştırmada, ilköğretim dördüncü sınıf öğrencilerinin görsel okuma becerisi ile okuduğunu anlama becerisi arasındaki ilişkiyi belirlemeye yönelik ilişkisel model kullanılmıştır.

\section{Evren ve Örneklem}

Araştırmanın evrenini Ankara ili Çankaya ilçesinde bulunan ilköğretim okulları oluşturmaktadır. Araştırmanın örneklemini, Çankaya

ilçesinde basit seçkisiz örnekleme yöntemi kullanılarak seçilmiş 52 dördüncü sınıf öğrencisi oluşturmaktadır.

\section{Veri Toplama Araçlarının Hazırlanması ve Geçerlik-Güvenirlik Çalışmaları}

Araştırmada, öğrencilerin görsel okuma becerisini ölçmeye yönelik Pixar tarafından üretilmiş beş adet grafik animasyon türü kısa filme yönelik sorular hazırlanmıştır. Beş adet görsel okuma testinin yanında okuduğunu anlama becerisini ölçmeye yönelik Bütün Gün Esneyen Prenses adlı bir okuma metni kullanılmıştır.

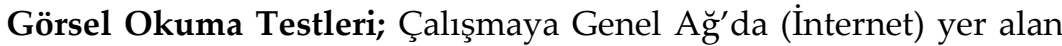
on beş Pixar kısa filmin öğrenci seviyesine uygunluk ve içerik açısından yeterlilik incelemesiyle başlanmıştır. Uzman görüşleri de alınarak beş film 
üzerinde görsel okuma ölçeği geliştirilmiştir. Filmlerin Genel Ağ'dan kolay ulaşılabilir olması ve ölçeğin öğrenci ilgisini çekecek nitelikte olması önem teşkil etmektedir.

Pixar tarafından geliştirilmiş orijinal adı“Presto, La Luna, Lifted, Birds ve One Man Band adlı kısa filmlerin izletilmesinden sonra uygulanan testlerde yer alan soruların bir kısmı, cevabı filmin içinde yer alan sorular $(5 \mathrm{~N} 1 \mathrm{~K})$ iken bir kısmı da yorum yapmayı gerektiren ve filmin verdiği mesaja yönelik sorulardan oluşmuştur. Yorum yapmayı gerektiren sorular 2,5 puan cevabı filmin içinde yer alan sorular 1'er puan olarak hesaplanmıştır Oluşturulan bu testlerin geçerlik güvenirlik değerlerinin belirlenmesi için testler 273 öğrenciye uygulanmıştır. Filmlerden sonra uygulanan görsel okuma ölçeklerinin güvenirlik analizi sonucunda elde edilen cronbach alpha katsayıları Tablo 1'de gösterilmiştir.

Tablo.1 Görsel Okuma Ölçeklerinin Güvenirlik Katsayıları

\begin{tabular}{ll}
\hline Filmler & Cronbach Alpha Değeri \\
\hline Presto & .84 \\
La Luna & .80 \\
Lifted & .83 \\
Birds & .82 \\
One Man Band & .85 \\
\hline
\end{tabular}

Ölçeklerin cronbach alpha güvenirlik katsayıları filmlerin orijinal adlarına göre Presto için .84; La Luna için .80; Lifted için .83; Birds için .82 ve One Man Band için .85 bulunmuştur. Cronbach's alpha değerinin 0.70 ve üstü olduğu durumlarda ölçeğin güvenilir olduğu kabul edilir (Sipahi, Yurtkoru ve Çinko, 2010). Bu araştırmada, ölçeklerin cronbach alpha değerlerinin .80 ve üzeri olması güvenirlik değerlerinin yüksek olduğunu göstermektedir.

Okuduğunu Anlama Testi; Carmen Gil tarafından yazılmış "Bütün Gün Esneyen Prenses" adlı metne araştırmacılar tarafından hazırlanmış çoktan seçmeli sorulardan oluşmuştur. Kitap İspanya Kültür Bakanlığından Resimli Çocuk Kitabı Dalında 2006 yılında ikincilik ödülü almıştır. Kitabın sadece yazılı metni kullanılmıştır. Okuduğunu Anlama Testi soruları cevabı metnin içinde olan beş soru ve cevabı metin dışı bir soru olmak üzere altı sorudan oluşmuştur. Okuma metni soruları hazırlanırken alanında üç uzman ile görüş birliğine varılmıştır. Çıkarım yapmayı gerektiren sorular 2,5 puan iken cevabı metnin içinde yer alan sorular 1'er puan olarak hesaplanmıştır. Test 52 dördüncü sınıf öğrencisine uygulanmıştır. 


\section{Bulgular ve Yorumlar}

Araştırmanın sorusu olarak cevap aranan "İlköğretim dördüncü sınıf öğrencilerinin görsel okuma becerisi ile okuduğunu anlama becerisi arasında bir ilişki var mıdır?" problemine ilişkin yapılan analiz bulguları Tablo 2'de sunulmuştur.

Tablo 2.

Görsel Okuma Becerisi ile Okuduğunu Anlama Becerisi Arasındaki Pearson Çarpım Momentler Korelâsyon Matrisi

\begin{tabular}{lcc}
\hline Değ̈iskenler & 1 & 2 \\
1-Görsel Okuma Becerisi & 1 & $.449^{*}$ \\
$2-O k u d u g ̆$ & $.449^{*}$ & 1 \\
\hline$\eta=52,{ }^{*} p<.01$ & & \\
\hline
\end{tabular}

Tablo 2'de görüldüğü üzere ilköğretim dördüncü sinıf öğrencilerinin görsel okuma becerisi testi ile okuduğunu anlama becerisi testinden elde ettikleri toplam puanları arasında [ $r=.44]$ pozitif yönde anlamlı ilişki saptanmıştır.

\section{Tartışma, Sonuç ve Öneriler}

Bu araştırmada ilköğretim öğrencilerinin görsel okuma becerisi ile okuduğunu anlama becerisi arasında bir ilişki var mıdır sorusuna yönelik bulgular; ilköğretim dördüncü sinıf öğrencilerinin görsel okuma becerisi testi ile okuduğunu anlama becerisi testinden elde ettikleri toplam puanları arasında [ $r=.44]$ pozitif yönde anlamlı ilişki olduğunu göstermektedir. Çam (2006) araştırmasında, ilköğretim okulu beşinci sınıf öğrencilerinin görsel okuma düzeylerinin okuduğunu anlama becerisi, eleştirel okuma becerisi ve Türkçe dersi akademik başarısı arasında anlamlı ilişki ortaya çıkmıştır. Araştırmanın dikkat çeken bir bulgusu da, öğrencilerin görsel okuma becerisi düzeylerinin evde kitle iletişim araçlarının bulunma sıklığı ve çeşidi artıkça yükseldiğidir. Dönmez (2013) görsel okuma alanında karikatürler kullanılarak 7. sınıf öğrencilerinin okuduğunu anlama ve yazma becerilerinin gelişimine bakmıştır. Araştırma sonuçları Türkçe dersinde karikatür kullanarak hedeflenen kazanımlara ulaşmada deneysel gruptaki öğrencilerin kontrol grubundaki öğrencilere oranla okuduğunu anlama ve yazma becerileri alanında daha başarılı oldukları sonucuna ulaşılmıştır. Kayhan (2010) ilköğretim birinci kademe sınıflara devam eden çocuklarda okuduğunu anlama becerisi ile sözcük bilgisi, görsel alg1, kısa süreli bellek ve okuma hızı arasındaki ilişkiyi incelediği araştırmasında; okuduğunu 
anlama ile sözcük bilgisi, görsel alg1, kısa süreli bellek ve okuma hızı arasında anlamlı ilişki bulunmuştur.

Ülkemizde görsel okuma ve görsel sunu alanına yönelik materyaller oldukça sınırlı imkânlarda okullarda kullanılabilmektedir. Öte yandan teknolojik gelişmeler görsel okuma çalışmalarının çocukların yaşantınsa ne kadar girdiğini göstermektedir. Microsoft'un beden dilini algılayan üç boyutlu animasyon oyunları ve akıllı tahtalar bu alanda yapılacak çalışmaların önünü açmaktadır. Araştırmanın sonucundan yola çıkarak okuduğunu anlama, görsel okuma ve hikâye haritası tekniği üzerine araştırmalar yapılabilir, Pixar filmlerinin görsel okuma ve yaratıcı yazma alanında kullanılması üzerine çalışmalar yapılabilir.

\section{Kaynaklar}

Arnheim, R. (1969) Visual thinking. Berkeley CA: University of California Press.

Balun, H (2008) İlköğretim ı. kademede uygulanan görsel okuma ve görsel sunu öğrenme alanının Türkçe öğretiminde kazanımlara ulaşmadaki etkililiği (Bingöl-Elazı̆̆-Diyarbakır örneği) Yayınlanmamış Yüksek lisans tezi. Elazığ: Firat Üniversitesi.

Çam, B (2006) Ilköğretim öğrencilerinin görsel okuma düzeyleri ile okuduğunu anlama, eleştirel okuma ve Türkçe dersi akademik başarıları arasındaki ilişki. Yayınlanmamış Yüksek lisans tezi. Eskişehir: Osmangazi Üniversitesi.

Debes, J.L. (1968) Some foundations for visual literacy. Audiovisual Instruction, 13, 961-964.

Debes, J. (1969). The loom of visual literacy: An overview. Audiovisual Instruction, 14(8), 25-27.

Dönmez, A. F. (2013) İlköğretim 7. Sinıf öğrencilerinin Türkçe öğretiminde okuduğunu anlama ve yazma becerilerinin gelişmesinde karikatürün etkisi. Yayınlanmamış Yüksek lisans tezi. Bolu: Abant İzzet Baysal Üniversitesi.

Epçaçan C., Epçacan, C. ve Ulaş, H.A. (2010) The study of visual reading strategies scale of validity and reliability in comprehension teaching. Procedia Social and Behavioral Sciences 9, 1666- 1673. Published by Elsevier Ltd. doi: 10.1016/j.sbspro.2010.12.383

Fries, C, C (1952) The structure of English: An introduction to construction of English sentences. New York: Harcourt, Brace and CO. 
Gibson, J. J. (1954) A theory of pictural perception. Audio Visual Communication Review, 2,2-23.

Gozemba, P. A. (1975) The effects of rhetorical traning in visual literacy on the writing skilss of college fresman (Doctoral dissertation, Boston University) Dissertation Abstracts International, 36, 1269.A (University Microfilms No. 75- 20, 950)

Kayhan, E. (2010) İlköğretim birinci kademe çocuklarında okuduğunu anlama ile sözcü̈k bilgisi, görsel algı ve kısa süreli bellek arasındaki ilişki. Yayınlanmamış Yüksek lisans tezi Ankara: Ankara Üniversitesi Sosyal Bilimler Enstitüsü.

Kuru, A. (2008). Illköğretim beşinci sınıf Türkçe dersi öğretim programında yer alan görsel okuma ve görsel sunu becerilerinin öğretmen görüşleri doğrultusunda incelenmesi. Yayınlanmamış Yüksek lisans tezi. Adana: Çukurova Üniversitesi Sosyal Bilimler Enstitüsü.

Milli Eğitim Bakanlığı [MEB] Talim ve Terbiye Kurulu Başkanlığı (2005). İlköğretim Türkçe dersi öğretim programı ve kılavuzu (1-5. Simıflar), Ankara: Devlet Kitapları Mudurluğu Basım Evi.

Moore, D. M. ve Dwyer, F. M. (Eds). (1994) Visual Literacy a Spectrum of Visual Learning. Theoretical foundations of visual learning. Chapter One.: J. A. Hortin, New Jersey: Educational Technology Publications.

Paivio, A. (1991) Images in the mind: the evolution of a theory. Great Britain: BPCC Wheatons Ltd, Exeter.

Shurtleff, S. J.(2006). Visual literacy as a method of understanding texts in the language arts classroom:storyboarding and video production. USA: Kent State University College. ID:1437563 "search.proquest.com" adresinden 15.07.2013 tarihinde erişilmiştir.

Wikipedia. (2013) Dual Coding Theory. http://en.wikipedia.org/wiki/Dualcoding theory adresinden 30.07.2013 tarihinde erişilmiştir.

\section{EK_1 \\ GÖRSEL OKUMA TESTI}

Film 1: Presto: Hizlı

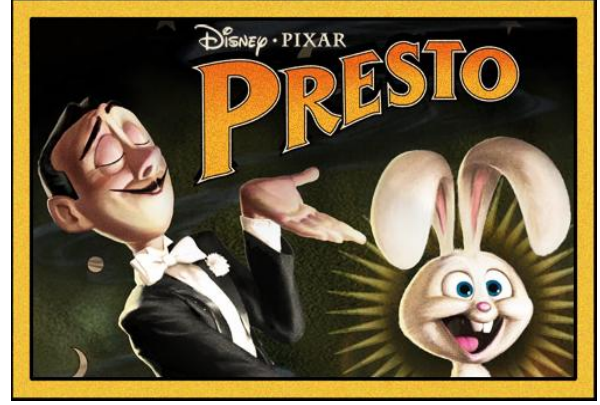




\section{Filmdeki problem nedir?}

a)Tavşanın aç olması.

b) Sihirbazın tavşana çok kızgın olması.

c) Şapkaların karışmış olması.

2. Olay nerede geçmektedir?

a)Gösteri salonunda

b)Sirkte

c) Parkta

3. Gösteri nasıl sonuçlanmıştır?

a) Seyirciler yumurta atmışlardır.

b)Sihirbaz sahneden kaçmıştır.

c)Seyirciler alkışlamışlardır.

4. Tavşan kimi kızdırmıştır?

a) Seyircileri

b)Sihirbazı

c) Müzisyeni

5. Filmin ana fikri nedir?

a)Karşındakinin ne istediğini anlamazsan sorun çıkabilir.

b) Yemeğini vermeyerek hayvanlara eziyet etmemelisin.

c) Sirkte eğitim almış bazı tavşanlar akıllıdır.

\section{EK_1 \\ GÖRSEL OKUMA TESTI}

Film 2: La Luna : Ay

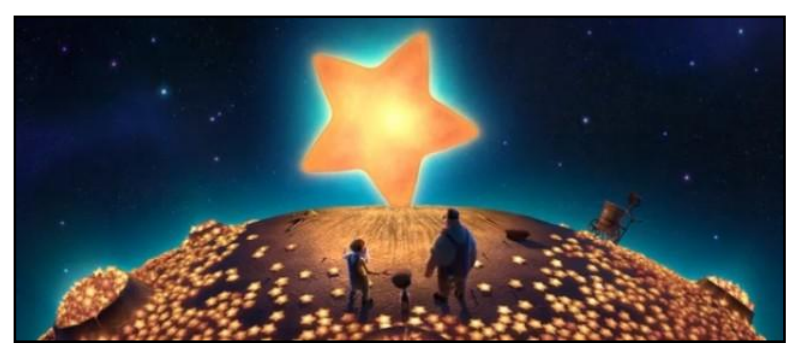

1.Filmde problem nedir?
a) Süpürgelerin kırılması
b) Baba ve dedenin anlaşamaması
c) Merdivenin Ay'a yetişmemesi
2. Baba, çocuk ve dede Ay'a nasıl çıkıyorlar?
a) Merdivenle
b) Çapa atarak
c) Her ikisi de 


\section{Büyük yıldızı yerinden oynatan kimdir?}

a)Dede

b)Baba

c) Çocuk

4. Olay nerede geçmektedir?

a)Dünya'da

b) Ay'da

c)Güneş'te

5. Olay ne zaman gerçekleşmektedir?

a)Gece

b)Gündüz

c)Öğlen

6. Filmin ana fikri nedir?

a) Babanı ve dedeni örnek almalısın.

b) Başkalarını taklit etmeden kendin gibi olmalısın.

c) Ay'ın çeşitli şekilleri vardır.

\section{EK_1 \\ GÖRSEL OKUMA TESTI}

Film 3: Lifted: Yukarı Kaldırma

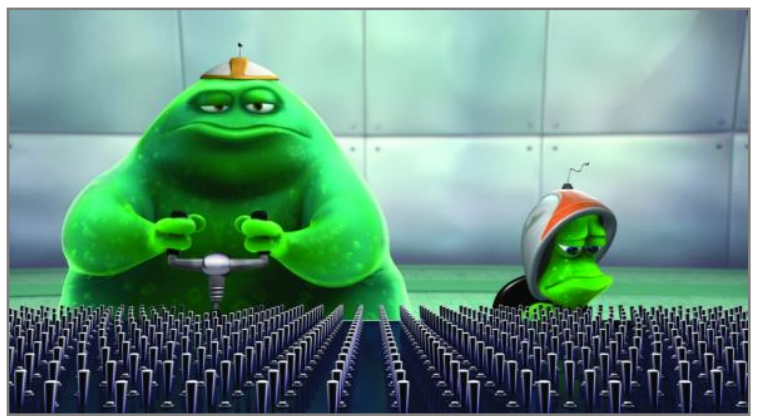

\section{Filmdeki problem nedir?}

a) Küçük uzaylının düğmeyle ilgili bilgileri kitapta bulamaması.

b) Adamın sürekli evin duvarına çarpılması.

c) Küçük uzaylının kumanda düğmelerini nasıl kullanacağını bilmemesi.

2. Uzay gemisi ne zaman gelmiştir?

a) Sabah

b)Öğle vakti

c)Gece yaris1

3. Uzay gemisini düşüren kimdir? 
a)Küçük uzaylı

b)Şişman yaratık

c)Uyuyan adam

4. Uzaylı, adamı evden çıkarmayı nasıl başarmıştır?

a) Zekâsı sayesinde

b) Şişman yaratıktan yardım alarak

c)Kitabı inceleyerek

\section{Filmin ana fikri nedir?}

a) İyi olmadığın bir konuda başkalarını tehlikeye atmamalısın.

b) Bilmediğin konularda kitaptakine göre hareket etmelisin.

c) Farkında olmadan bozduğun şeyleri düzeltmelisin.

\section{EK_1 \\ GÖRSEL OKUMA TESTI}

Film 4: For the Birds: Kuşlar İçin

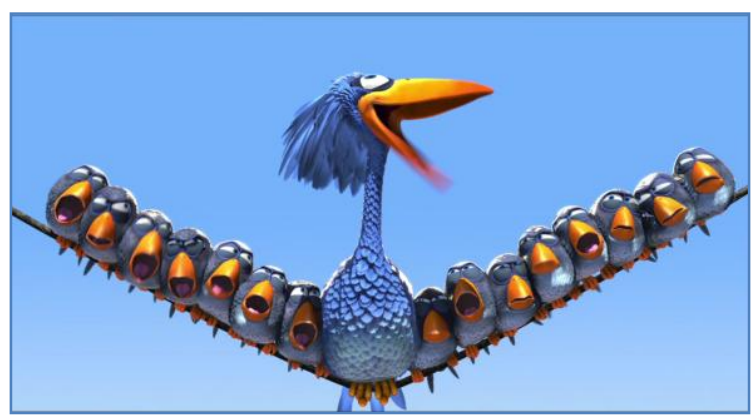

\section{Filmdeki problem nedir?}

a) Küçük kuşların telden düşmesi.

b) Büyük kuşun küçük kuşları telde istememesi.

c) Küçük kuşların kendilerinden farklı bir kuşu telde istememesi.

2. Kuşlar neden büyük kuşu aralarında istemiyorlar?

a) Telin üzerinde yer olmadı ̆̆ 1 için.

b) Kuş büyük olduğu ve onlara benzemediği için.

c) Büyük kuştan korktukları için.

3. Sonuçta kuşlara ne oldu?

a) Tüyleri döküldü.

b) Uçup gittiler.

c) Büyük kuşla eğlendiler.

4. Olay nerede geçmektedir?

a) Elektrik tellerinde 
b)Çamaşır ipinde

c)Bir evin çatısında

5. Olay ne zaman gerçekleşmektedir?

a) Sonbahar

b)Kış

c) İlkbahar

6. Tüyleri dökülmeden yere inen kimdir?

a) Büyük kuş

b) Küçük kuşlar

c)İkisi de

7. Filmin ana fikri nedir?

a) Kendinden küçüklere zarar vermemelisin.

b) Başkalarını dışlarsan kendin zararlı çıkarsın.

c) Birlikten kuvvet doğar.

EK_1

GÖRSEL OKUMA TESTI

Film 5: One Man Band:

Tek Kişilik Bando

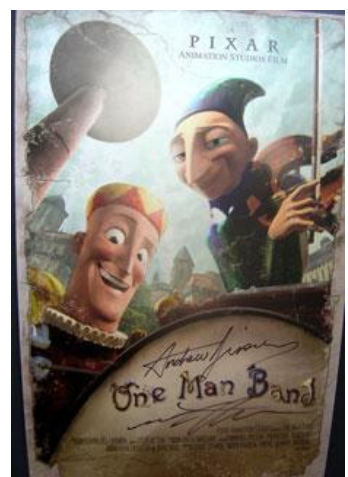

\section{Filmdeki problem nedir?}

a) Çocuğun elindeki parayı ne yapacağına karar verememesi.

b) Çocuğun aynı anda iki adamı seyredememesi.

c) Adamların çaldığı müziğin çok karmaşık olması.

2. Olay nerede geçmektedir?

a) Bir havuzun başında

b) Parkta

c) Müzik salonunda

3. Çocuk ne zaman çok paraya sahip oluyor?

a)Parasını bando adamlarla paylaşınca. 
b) Kendisi keman çalınca.

c) Parasını suya atınca.

4. Paralar sonunda kimin oldu?

a) Davul çalan adamın

b)Keman çalan adamın

c)Küçük kız çocuğunun

5. Bando adamlar küçük kıza nasıl davrandılar?

a)Yardimsever

b)Israrc1

c)Şüpheci

6. Filmin ana fikri nedir?

a) İnsanları zorlayarak rahatsız etmemelisin.

b) Bir insan birden fazla müzik aleti çalamaz.

c) Küçük çocuklar keman çalmada çok yeteneklidirler.

EK_2

OKUDUĞUNU ANLAMA TESTI

\section{Bütün Gün Esneyen Prenses}

$\mathrm{Bu}$, sarı bir sarayın, altın taçlı Kral'ın ve bütün gün esneyen bir Prenses'in öyküsüdür. Kral bütün gün, kraliyet halısının üzerinde bir yukarı bir aşağı, bir aşağı bir yukarı yürüyüp duruyordu. Çok büyük bir derdi vardı: Kızı esnemekten başka hiçbir şey yapmıyordu! Esnerken ağzını o kadar çok açıyordu ki avare uçuşan bir sinek, yolunu şaşırmış bir sinek kuşu ve menekşe rengi bir kelebek ağzına kaçmıştı. Esneme bulaşıcı olduğundan bütün saray, ağzı açık dolaşır olmuştu: Kral esniyordu, kraliçe esniyordu, bakanlar esniyordu. Bahçıvanın kedisi ile köpeği bile esniyordu! Prenses neden bu kadar çok esniyor? Diye düşündü Kral kendi kendine. Karnı mı aç acaba? Bu olasılığı düşünerek uzak diyarlardan en lezzetli yiyecekleri getirtti: İtalya'dan dondurma, Çin'den pilav, Brezilya'dan kakao, Japonya'dan çiğ balık, Tayland'dan çekirge kızartması... Prenses bu yiyecekleri tıka basa yedi, fakat esnemesi bir türlü geçmek bilmedi! Kral, Kraliçe ve bakanlar... Hatta bahçıvanın kedisi ile köpeği bile esnemeye devam etti! Hala endişeli olan Kral yine kraliyet halısının üzerinde bir yukarı bir aşağı, bir aşağı bir yukarı yürüyüp duruyordu. "Prenses neden bu kadar çok esniyor? Uykusu mu var acaba? “

Bu olasılığı düşünerek şiltesi kuştüyünden, çarşafları ipekten ve cibinliği satenden yumuşak bir yatak sipariş etti. Ayrıca Prenses'in odasına, kokulu 
gül yaprakları serpiştirilmesini de emretti. Mandolin çalıp tatlı ninnilerle Prenses'i uyutması için o bölgenin en iyi şarkıcısı getirtti. Şakacı bir güneş ışını pencereden girip saçlarıyla oynamaya başlayıncaya kadar Prenses derin bir uyku çekti fakat esnemesi yine geçmedi! Kral, Kraliçe ve bakanlar hatta bahçıvanın kedisi ile köpeği bile esnemeye devam etti!

Uzun uzun kafa yorup bir yukarı bir aşağı yürümekten ayakkabılarının tabanı aşınan Kral, bir kez daha kendi kendine sordu: Prenses neden bu kadar çok esniyor? Canı mı sıkılıyor acaba? Bu olasılı̆̆ı düşünerek herkesi gülmekten kırıp geçiren, fıkralar anlatan sarı bir fil getirtti komşu krallıktan. Fakat Prenses'in esnemesi geçmedi! Haber şimşek hızıyla yayıldı. Çok geçmeden komşu ülkelerde sarayın bu sorununu duymayan kalmadı. Dört bir yandan akın akın şarlatanlar ve şifacılar geldi. Fakat Prenses'e içirdikleri onlarca şuruba, sürdükleri onarca merheme rağmen prenses esnedi de esnedi!

Bir gün Prenses bahçede yürüyüş yaparken sarayda çalışan uşaklardan birinin oğlu yanına yaklaşmak istedi. Zavallı çocuk öyle heyecanlandı ki bir meşe ağacının köklerine takılıp fıskiyeli havuzun içine düşüverdi. İliklerine kadar ıslanmış halde havuzdan çıktığında ağzından renkli bir süs balığı, kulaklarından da birkaç yengeç sallanıyordu. Bunu görünce Prenses kahkahayı koyuverdi, on beş dakika ha ha ha hi hi hi diye güldüğünden bir kere bile esnemedi. Tir tir titreyen ama Prenses'in kahkahalarla gülmesine sevinen çocuk sonunda şunları söyleyebildi "Zür Irim Rrpenses." Bu cümle dili dügümlenenlerin dilinde "Özür dilerim Prenses anlamına geliyordu." Çocuk konuştukça kız güldü. Kız güldükçe çocuk konuştu. "Jamesteleri, diheyemi kalub ederek nebi orullandırır mısınız?" Bu cümle dili düğümlenenlerin dilinde "Majesteleri hediyemi kabul ederek beni onurlandırır mısınız? " anlamına geliyordu. Uşağın oğlu, pancar gibi kızararak Prenses'e küçük, tahta bir kutu verdi. Kutuyu açınca Prenses'in yüzüne kocaman bir gülümseme yayıldı. Kutuda, o zamana kadar gördüğü en parlak, en yeşil kurbağa duruyordu. Çocuk Prenses'i çekirge yakalamaya, teperlerden aşağı yuvarlanmaya, terk edilmiş bir şatoda hayalet aramaya, göle dalmaya, elim sende oynamaya, yüzünü çamurla boyamaya ve Prenses'in oynaması yasaklanan bütün oyunları oynamaya götürdü. $O$ günden sonra arkadaş oldular. Prenses esnemeye son vermişti. Kral, kraliçe ve bakanlar hatta bahçıvanın kedisi ile köpeği de esnemeyi kesmişti! Prensesleri ne İtalya'nın dondurması, ne kuştüyü döşekler ne de sarı filler mutlu edebilir. Bir insanın kalbini ancak iyi bir arkadaş aydınlatabilir.

Carmen Gil 